\title{
'Delightfully depressing': Death/doom metal music world and the emotional responses of the fan
}

\author{
by M Selim Yavuz, Leeds Beckett University, msy@mselimyavuz.com
}

Originally published in Metal Music Studies Journal volume 3 issue 2, published by

Intellect in June 2017.

http://www.ingentaconnect.com/contentone/intellect/mms/2017/00000003/00000002/art

$\underline{00003}$

doi: $10.1386 / \mathrm{mms} .3 .2 .201 \_1$

Suggested citation: Yavuz, M. S. (2017), “ “Delightfully depressing”: Death/doom

metal music world and the emotional responses of the fan', Metal Music Studies, 3:2,

pp. 201-218, doi: 10.1386/mms.3.2.201_1

OA pre-print version with the permission of Intellect Ltd.

\begin{abstract}
Death/doom metal music, from both sides of the name, usually occupies itself with the darker spectrum of human emotion. Depression, melancholy, and death are common themes in the music and in the reception of this music from an outsider point of view. In line with symbolic interactionism, these emotional responses differ significantly when they originate from a well-socialized member of this music world. This suggests that one may think of emotional responses as conventions of a music world. Common responses provide an emotional repertoire for members, and furthermore they become an adhesive for the community. In this article, I discuss my research of the fans of death/doom metal, and explore the ways in which the fan responds to the music while contemplating on how death/doom function in the lives of these fans.
\end{abstract}

Keywords: doom metal, emotional response, extreme metal, music worlds, metal categorization, symbolic interaction

Death/doom metal is a style of metal music originated in the early 1990s with mainly three bands: My Dying Bride, Paradise Lost, and Anathema. While geographically this style seems to be localized to northern England, with its immediate spread in the early 1990s the style became and remains a global one. I will not go deep into the style of this music here as it is more appropriate for another discussion. However, a brief mention of the style might be beneficial to the reader. Death/doom is a style that can be considered be part of extreme metal. The style has elements from both death metal and doom metal music, and my interviews with musicians so far suggests that it is slowed-down death metal, rather than 'death'ened doom metal. The addition of keyboards and in the case of My Dying Bride violins to the standard orchestration of metal music (electric guitars, bass guitar, drum set, and human vocals) differentiates this style from its contemporaries. One of this style's crucial aspects is the musical contrast. A typical example of this style is My Dying Bride's 'Turn Loose the Swans' from their album Turn Loose the Swans (Peaceville Records, 1993).

Death/doom metal has a liminal space in metal world and in even extreme metal (Yavuz 2016). I turn to one of my participants here as I think they put this position nicely:

[My Dying Bride] are not like Black Sabbath or Emperor about whom you can talk to pretty much anyone in the metal community and they will have some sort of an 
opinion. I find that bands like My Dying Bride are kind of like Marmite: you either really really like them or you really don't. I don't really find that there's ever really any in between with bands like that. (Gamzette $\left.{ }^{1}\right)$

In this paper, I discuss not death/doom the style, but death/doom the music world (Bottero and Crossley 2011; Crossley 2015a; Crossley 2015b; Crossley and Bottero 2015a; Crossley and Bottero 2015b; Crossley et al. 2014; McAndrew et al. 2015; O'Shea 2015; Prior 2015) and discuss the fan emotional responses within this music world, the one which was constructed around the musics of My Dying Bride, Paradise Lost, and Anathema and how these responses might contribute to the construction of a music world through conventions. There have been many different perspectives on communities under the 'extreme metal' (in Kahn-Harris' [2007] terms) umbrella, especially black metal cultures in metal music studies (see Hagen 2011; Kahn-Harris 2004; Kuppens and van der Pol 2014; Larsson 2013; Spracklen 2015; Varas-Diaz and Scott 2016; Venkatesh et al. 2015; Wallach et al. 2011), however death/doom metal community has been largely ignored.

Music worlds, according to Nick Crossley, are social spaces that are 'centered upon a self-identified musical style; a space set aside from other concerns, at least to some extent, where music is a primary focus and where participants share a set of musical preferences and knowledge' (2015a: 472). In this paper, I discuss the approach to the ethnographic data and the method at first before going into the results of the research. After this introduction, this paper focuses on the individuals' emotional responses to these bands' musics and how these responses can be interpreted collectively or individually while considering the responses of the participants regarding their own community.

\section{Researcher Position}

At this point, I think it would be beneficial to clarify my position and perspective as the researcher within this music world before going into the demographics of the participants. As of this writing, I am a 30-year-old male born and raised in Turkey coming from a middle-class background with an academic family. I have been listening to My Dying Bride and Anathema since 2002, and Paradise Lost since shortly after that, and identified myself as a fan since then. I am an amateur doom metal musician with only unpublished compositions and an amateur photographer specializing in metal concerts. I have written album and concert reviews of doom metal bands in several blogs and as of this writing, I continue to do so. This is important, while my methodology does not employ autoethnography, my perspective is inescapably affected by my already existent position in the music world in question.

Merleau-Ponty posits a notion of the "institution" of personal history, which is intended to capture the process by which repeated responses and forms of understanding and interpreting become sedimented in our praxes over time, giving rise to stable preferences for certain types of response. This extends to the sphere of emotion [where] we acquire and develop an individual emotional repertoire [...] or an emotional habitus. (Crossley 1998: 33)

Thus, the interpretation of the emotional responses discussed in this paper are only results

\footnotetext{
${ }^{1}$ All participant names are anonymised. Please see Methods section for details.
} 
of my 'emotional repertoire'.

\section{Methods}

I interviewed fans of My Dying Bride, Paradise Lost, and Anathema in order to get responses about how the fans define the culture they belong and in order to probe how this musical style affects people who decide to engage with the culture surrounding the musical style. I collected participant responses using interviews via different media ${ }^{2}$. The bands My Dying Bride and Paradise Lost among many other fan clubs, and Northern Music Co helped me recruit participants. During the initial interview with Aaron Stainthorpe from My Dying Bride, Aaron offered to take the project's recruitment flyers on their Europe tour for the album Feel the Misery (2016) and post the flyer on the band's Facebook page. Upon the post on Facebook, I received 191 e-mails stating interest in the participation of the project in approximately one week and as of this paper, the flyer post of My Dying Bride on Facebook has 2081 'reactions', 130 comments, and 486 shares. This response is an indicator of the involvement of the members of this music world and their support regarding a research of their culture. This response resulted in 74 interviews with 74 participants in the spring of 2016.

Potential participants were offered to give interviews via phone, e-mail, social media, online conferencing, and in the cases where participants resided in northern England and they agreed face-to-face. All interviews were conducted in English apart from two interviews which were conducted in Turkish. All the questions were posed as optional including the demographic data and personal background questions. For most participants (including all e-mail interviews with the exception of two participants where I asked follow-up questions in second and third e-mails), I asked a set of 22 questions. The responses you see in this article are responses to the question 'How do you feel when you are listening to the music of My Dying Bride, Paradise Lost, and Anathema?'. However, some participants talked about these emotional responses when they were discussing their first experiences with these bands, their journey to becoming a fan, or when they were comparing this style of music with others. More wide discussion of these responses is beyond the scope of this article.

\footnotetext{
${ }^{2}$ This research is done as part of my self-funded PhD project at Leeds Beckett University (LBU) in the United Kingdom. The project has received ethical approval from the Local Research Ethics Committee of LBU Carnegie Faculty, and it is in line with LBU Research Ethics Policy (http://www.leedsbeckett.ac.uk/studenthub/research-ethics.htm).
} 


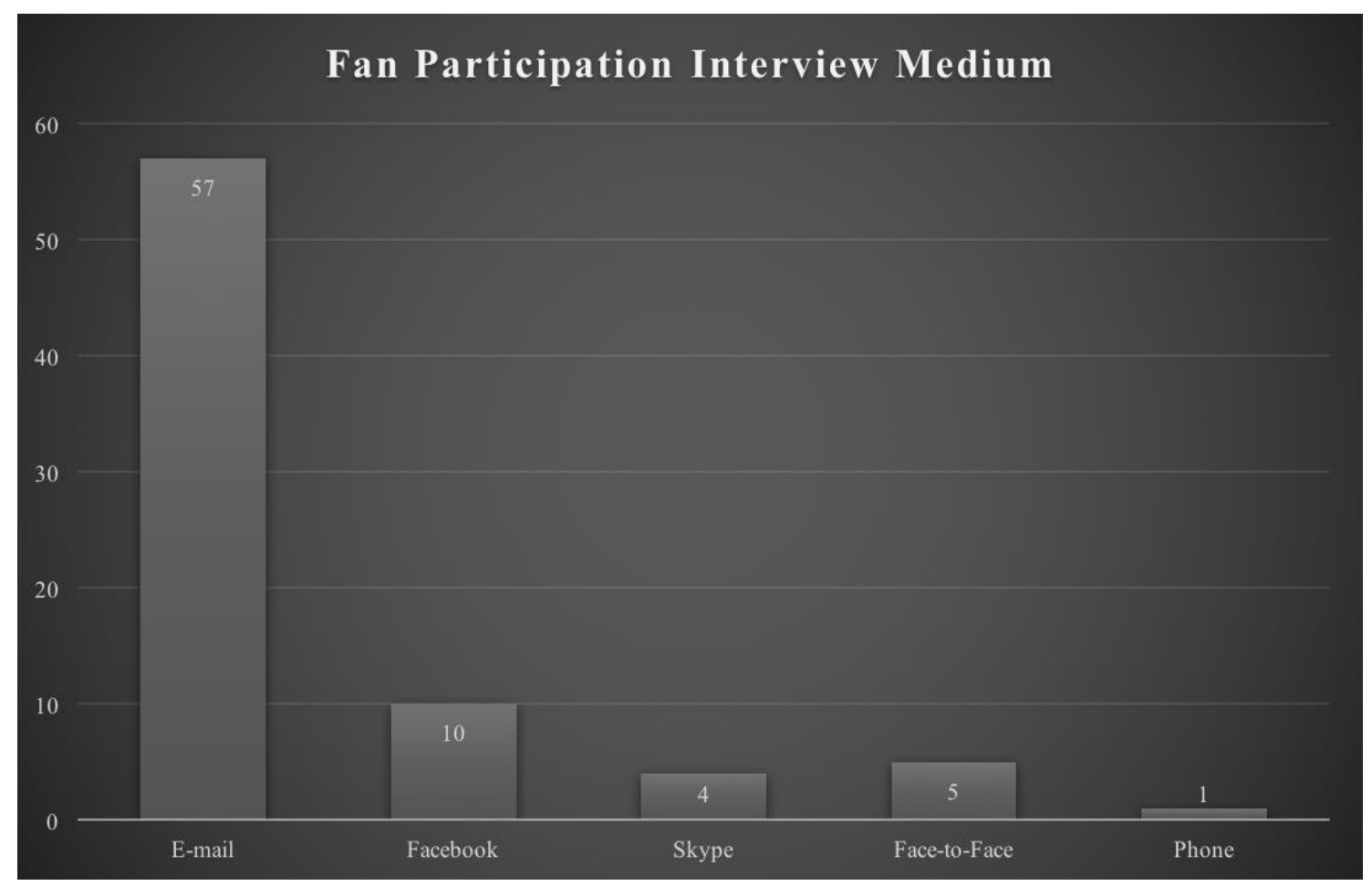

Figure 1 Participant distribution of interview types

All the names of the fan participants have been changed in this paper except for two where their first names are used as per their request. The names are surnames taken from the index of Atkins' book The Moor: Lives, Landscape, and Literature.

\section{Emotional response as part of communal identity}

How can one think of emotional responses as building blocks of a community or a social identity? Community or social identity inherently requires a sense of belonging. According to de Rivera (2014: 217), this feeling of belonging 'must' be constructed. Vikki Bell also suggests that a person cannot 'simply or ontologically' belong to a group, but it is an 'achievement at several levels of abstraction' (1999: 3). In this music world, emotions or rather emotional responses emerge as the prime suspect of a possible way of constructing a belonging. Moreover, the word 'belonging' has within the idea of affect. An 'affective dimension' comes into 'belonging', because it is 'not just be-ing but [also] longing' (Bell 1999: 1). However, one should also consider the viability of a construction based on emotional responses of participants of that social structure. Crossley argues (1998: 19):

What makes [...] intersubjective structuring [using emotions] possible [...] is that the grammar of the emotions language game is tied to what is publicly observable. It applies to actions and circumstances rather than private sensations. Emotions are constituted as meaningful responses to situations.

Then 'the grammar' of emotional responses can be considered to provide a common ground for a community; a set of symbols (Atkinson and Housley 2003; Blumer 1998; Charon 2010; Denzin 1992; Gilmore 1990) that participants may employ for interaction within the music world.

I insisted so far on the term 'emotional response' rather than just 'emotion', because while 'emotion' is an individual concept which means drastically different things 
for different individuals, a response is social, even when it is a response between the individual and the self ${ }^{3}$ and in the case of social networks (and with extension, music worlds) even in the absence of a direct personal relation (van der Löwe 2014: 130). Moreover, individuals use emotional responses to communicate information about who they are, how they wish to be treated, and how they feel about situations (van der Löwe 2014: 125). Emotional responses are 'rational' in a Habermasian communicative rationality interpretation.

Like any cognitive belief, an emotional response is something that we believe we can talk people out of when they are wrong (i.e. when their emotional response is irrational). Thus there is no reason why our social worlds cannot be simultaneously constituted through emotion and communicative rationality. [...] What it means, more precisely, to say that emotions form part of the sphere of communicative rationality is that they can strike us as either appropriate or inappropriate, rational or irrational, that we find them perfectly intelligible when we encounter them in others, that we explain them in terms of reasons rather than causes and that we hold people responsible for them, just as we do for any other of their actions." (Crossley 1998: 30)

These symbols within a music world would suggest a sense of community beyond the music involved.

Emotional responses are important from another perspective as well. Emotions are embodied phenomena; we observe emotion both physically and mentally. Crossley states that "the "body" involved [in emotional response] is a communicative agent rather than a mechanical being. The corporeal dimension of emotion is not a thirdperson physiological process but engaged and expressive praxis' (1998: 23). When we consider 'the body' an agent, the ways of embodiment contribute to the conventions of a music world and furthermore they become 'human capital' (Crossley 2015a: 483). Following the same line of thought and adding Bell's argument which states that the effect and affect of affiliation are also embodied processes (1999: 8), the emotional response become an important act that members of a music world can perform within the conventions to strengthen or deepen their belonging in the music world.

As [Anne-Marie] Fortier writes, the highly-ritualized movements that one performs in Catholic Mass are the incorporation of norms, a "stylized repetition of acts" that cultivate the sign and the sense of belonging [emphasis by me]. Moreover, she suggests that since it was in her study, performed within a non-Catholic country, the communal activity of Mass produces an attachment of the group to the site of its performance. Through embodied movements, the citation operates to recall and reconnect with places elsewhere that, through those very movements, are remembered; at the same time, a site of diasporic belonging is created. (Bell 1999: 3)

Fortier's research exemplifies how this can work in a social environment, however, more importantly, it illustrates how these embodied practices can create belonging to a separate 'diaspora' within a super-group. I take the death/doom music world as a diaspora here

3 'The self' here means the individual in a symbolic interactionist sense as discussed in the literature review. 'The individual' means the material agent. According to Williams, 'for individuals to understand their own lived emotions, they must experience them socially and reflectively' (1999: 127). 
formed within the music worlds of extreme metal, death metal and doom metal. Just as a diaspora, the differences of death/doom world are "sustained and produced on several levels and in complex ways, both within and beyond "the subject" (Bell 1999: 5); the subject being here the music. This idea comes in handy at the end of this paper where I will discuss a possible (or probable) community of death/doom metal music fandom.

\section{Sense of community and friction}

One of the important ways a fan can cultivate a sense of belong is through differentiating and conflict that comes with that differentiation. It is who they are and to what they feel or not feel like they belong. The divide on opinion regarding whether there is a doom or more specifically death/doom community exists is significantly large. Out of $70^{4}$ participants, 9 of them stated that they feel like they belong to, not a doom community, but they felt that they belonged to a large metal community. The sentiment among these participants are towards unity, and one of the main reasons for this emerges as their involvement with other styles and cultures within metal music.

I honestly don't feel part of a doom metal community; however, I feel as part of the metal community as a whole instead. (Bancroft)

I'm not sure if I've ever felt part of a specific doom community. I see it as an extreme metal community or just a metal community. (Garrs)

There are couple of interesting things to notice here, starting with the sense of restriction. Avoiding restriction and inclusion can be thought to be part of this music world. The death/doom fan sees themselves as open-minded, and free of restriction. The openmindedness gets mentioned specifically.

Well, most of my friends are fans of gore/death/thrash metal and some of them like Anathema because they have an open mind. Fans of Anathema are open-minded, you know. (Crabtree)

[Doom fans, in my opinion, are] more thoughtful, autonomous and free-thinking with a romantic sentiment. (Froissart)

Another idea is the perceived discreteness of a death/doom culture. While these participants think themselves to be something larger, the nuanced doom community is still articulated through an idea of separation. 26 out of 70 participants support this idea of separation in their allegiance or belonging.

I feel like I'm the part of doom metal community because of my musical taste, state of mind and soul, the way I'm dressed. I feel different at doom metal concerts than in perhaps folk metal concerts. (Babbage)

I would consider myself as a member of the doom community because I am contributing music into it, even if I don't have much interaction with people who

\footnotetext{
${ }^{4}$ This is 70 out of 74 interviews as stated before. The reason four participants are missing is because they chose not to say anything about what they think about community.
} 
consider themselves doom fans. I feel that this is more important. [...] Doom is a smaller subset of the larger metal community, so while we associate with the more general community, there is a certain fellowship through the mutual appreciation of doom. (Brooks)

I've never joined a forum, but often felt like part of the family at shows. (Fawkes)

Because there's quite a lot of [one day festivals] going on in Manchester, and there's always a strong group of women who are there, who some people actually like to affectionately refer to as "women of doom". I feel like I'm a bit of part of that.'(Gimzatte)

According to a significant number of participants, this separation from the larger cultural context exists, and furthermore they feel like they belong to something separate as well. Here is where the dissonance among the participants comes in. While 50\% (out of 70) of the participants feel part of metal community either in their smaller context or as a whole, there are another 35 participants, who have strong feelings towards a dismissal of such a community existing to begin with or as these participants state, even if it does exist, their rejection of belonging to such an entity.

Listening to music is a personal experience; I don't feel to be part of a community. I like talking with other guys about the music I love, but every one of us feels the music, especially this kind of music, in a very personal way. (Auden)

I don't feel a part of a community. I wouldn't like to be a part of a community. (Berry)

No, absolutely not. [in response to the question asking whether they feel part of a doom community]. (Brady)

I have to say when talking about metal communities, I'm just like with my nationality: yes, I'm Chilean and a metalhead, but I don't feel like being part of a Chilean or a metalhead community directly. I despise nationalities as much as I despise metal labels. (Douglas)

I am part of nothing. I feel that although I could share many feelings with other people, I do not like being part of a community. (Graham)

I think that this is a convention of the music world as well. When we analyze the reasons that people give for feeling this way, we see three patterns. Firstly, participants feel like they do not belong because either they see themselves inactive, i.e. only listening to the music or going to the concerts (Fowles; Hannam), or they deliberately stay inactive through only listening to music or going to the concerts (Auden; Berry). But this inactivity aligns with the activity of the participants who feel part of a doom community. For example, for one participant (Armstrong) the sole previous engagement with internet forums is enough for a community; at the same time for another participant the same activity is not. This supports my argument that the feeling of isolation is a convention of this music world. The second pattern is where the participants are very individualistic and do not be labelled with anything (Douglas; Froissart; Graham). This individuality resonates well within the music world in general. The connotations of these are already 
observed in the previous excerpts. More so, however, doom world members being highly individualized is something that comes up often among the participants.

At most you will find two or three bands [in doom metal] that resemble each other. If you take power metal or thrash metal, you will find hundreds of bands that sound like each other. (Carew)

It's part of the whole [metal community] but I think doom metal community is very peculiar. I think black and doom metal communities are both elitists in some way. Because they detach themselves from others somehow. When I look at my other metal friends, they have a certain view of their own style that is very peculiar. People who define themselves in thrash metal or death metal, you have more communication among them, but doom metal starts itself as something else I think. (Ellison)

Ellison's statement here ties into the third pattern where the participants stated that they do not feel part of a community because they feel that other people are not as well-versed as themselves (Carew). In one participant's terms, the belonging of a fan comes from their knowledge of the music world. Only a well-socialized member (Becker 2008) of this music world can be 'the actual fan'.

One important feature of this music world that it is a small one and in relation, it is bound to stay underground. This state of underground is a commonly accepted state: 'Doom is doomed to never be a commercial proposition' (Terrorizer issue 143 2006: 43). However, this does not change the fact that 'there has always been a hardcore and devoted following and enthusiasm [in doom metal]' (Terrorizer issue 14 1994: 12). It is a community that is 'more reclusive, and elusive than most music groups' (Bute).

If there was a doom community, it would hardly be more than 10 of us! (Gumb)

Only a few keep [doom metal] alive, and they don't depend on Kerrang! or Metal Hammer to tell them what to listen to. (Haworth)

The word 'doom' in this music world seems to carry a literal meaning within the culture. Because it is small and 'reclusive', the community has an impression of anguish and mourning.

Music in my opinion should feel beyond the letters. It is difficult to [feel] entirely from music when you listen to genres like thrash metal. [In thrash metal] you can feel the hate, the music is fast and strong and you focus [on] those feelings, but it is easier to release all that anger for your own problems when you listen carefully to those demons [within you] and ask why no other music [than doom metal], based on my perception, can give you this opportunity to hear and then feel the pain, sadness, melancholy, anxiety of this world your own unique world and [the world] we call reality that nobody wants to think. (Betjeman)

I have always found Paradise Lost and My Dying Bride quite deep and serious. A lot of death doom portrays tragedy, loss, mourning, depression, isolation and apocalypse. That speaks to me much more than some juvenile goregrind band obsessed with brain eating zombies or some power metal band obsessed with big swords. (Carew) 
There is a convincing emotional common ground among the participants. This is further supported by a sense of 'close-knit' (Allsop) community also in relation with the size of it.

As there are not that many people involved, the doom metal scene is some kind of a big family. (Hartley)

This 'family' idea brings forth a sense of sincerity in this music world as well.

The same people who are still a part of the doom social group are for the most part the same people who would join a long hike up into the mountains bearing instruments to do our folk meeting-jam-session whereas those who have since dispersed were largely the ones who would only join a folk gathering if it was at a location accessible by car. Sincerity is a definite personality trait of doom fans, in my opinion. (Allsop)

[Some friends who listen to doom metal] are posers, for they don't appreciate the whole meaning of doom metal; while others are more like me, and by that I mean not a comic-book-heavy-metal-fan-character. That is the step that differentiates doom metal from most other metal genres. [...] The authentic fan I mentioned [...] has a spirit that is also found in fans of classical music, especially of the romantic age, fans of the Gesamtkunstwerk of [Richard] Wagner, and that kind of stuff. They want it all, not just the appearance of all (at least not all the time - I am not a crazy radical, as you can see from the wide spectrum of music I listen to... But sometimes I need more than just that power feeling that almost every good heavy metal tune gives). (Baker)

Doom is an alternative niche within an alternative community, it is not flashy enough to be listened to to appear cool or popular enough to be listened to because all your friends do. As such most people I have encountered who listen to doom do so because they like the music, this being the main criteria of being a doom fan, along with the diverse range of sub-genres and fusion style, mean that doom fans are more free to just be themselves. [...] The true aesthetics of music is a many-faceted thing which no single genre can ever truly hope to fully express, but the glimpses of such ideal that doom can express are some of the most honest images of it. (Brooks)

I don't think their intention is to be "metal"; it happens to be, when you want to express this kind of feelings and thoughts. And I still think they are honest. The music or lyrics is being suffered and is self-referential. (Grimshaw)

In this case, I think it's the honesty. There's no cliché or mask you could wear; because very few people listen to that music, it won't benefit you if you fake it. Either you love it or you don't, there's no in-between. (Hartley)

The small community idea is further reflected in these responses, and more so because it is small sincerity comes from that. It is also important to note that this sincerity comes up usually in two ways: one where the fan notices sincerity in doom metal fans, and one where the fan sees insincerity in the outside. So, the latter suggests a comparison, and this has different connotations. I contend that the comparison can be a friction illustrating the 
relative position of the music world rather than only as a convention.

It is not surprising for anyone who is an insider to any metal culture that friction among metal cultures and extra-metal cultures exists prominently. The participants of this research proved no different than the expectation. This friction is important because it exhibits the music world's desire to separate themselves culturally from others. To give you a clear idea of how common sentiments of antagonism with other cultures than death/doom or doom metal: 49 participants out of 74 uttered words of conflict in 116 instances. This theme ended up being, by far, the largest among the participants' responses. There has been excerpts from participants so far which have these same ideas. I do not discuss these ideas of conflict in detail as they are out of scope of this paper but I move on to emotional responses to this music and culture from within the music world.

\section{Emotional responses as conventions of the music world}

As I mentioned earlier, emotional responses indicate belonging. This can be through a common response to a symbol existing in this culture. Finally, I will discuss these emotional responses of the participants in order to demonstrate how a common response is employed within the music world elevating that response into a convention status. I already talked about how the music is perceived from the outsider perspective using the insiders' perspective. The expressed conflict shows that this music requires effort to be understood; and its minimal and slow nature tends to make people who are not willing to put the effort, i.e., the outsiders, in this music feel bored. But how does the fan feel about this slow and minimal music? Examining the insider responses shows the change in understanding of musical and cultural symbols in this music world.

In my analysis of the participants' interviews, I categorized the emotional responses into 18 emotions. These are sometimes overarching, but in most cases, they represent something more specific. 


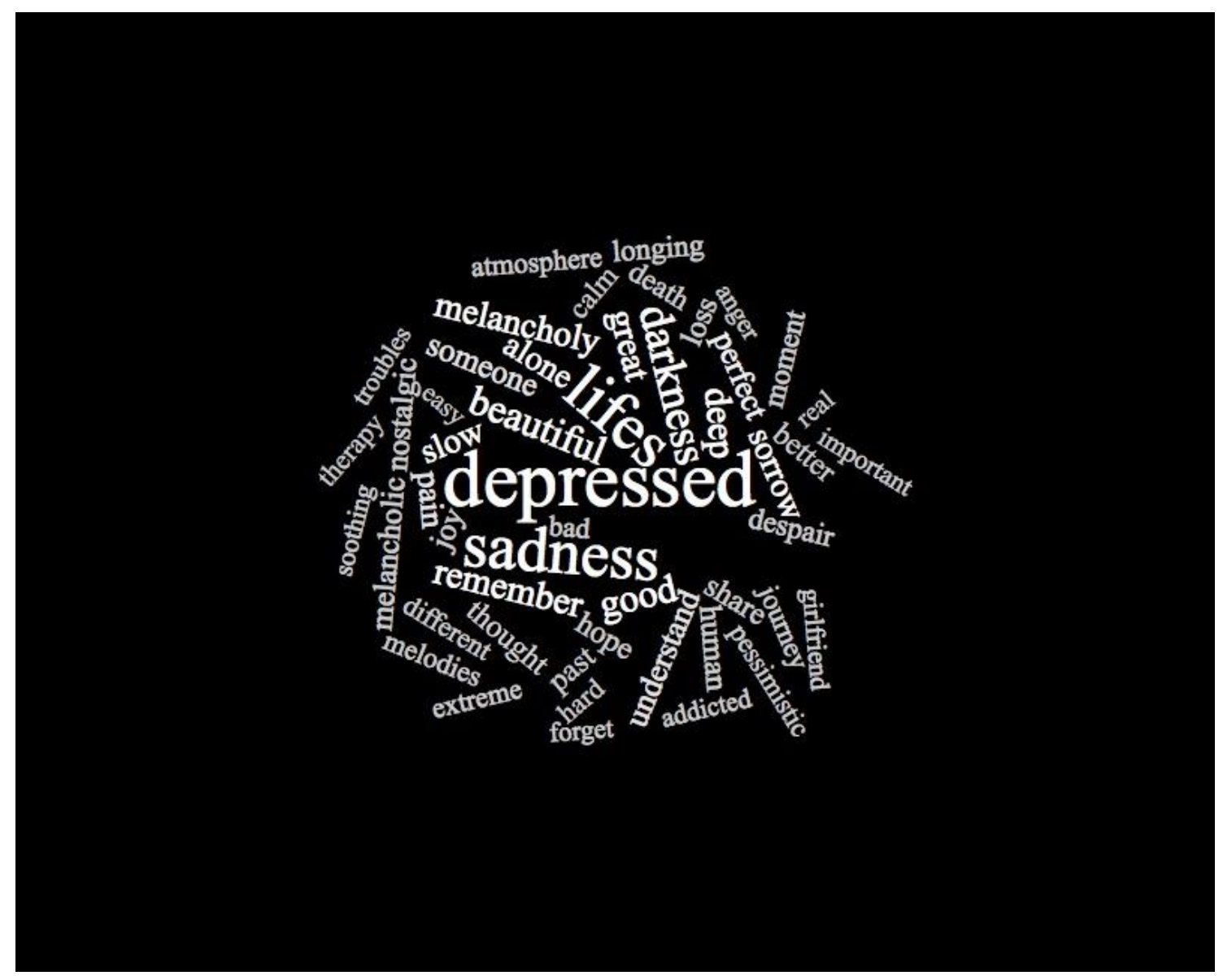

Figure 2 Word frequency cloud of participants in their responses related to the emotional response categories

Firstly, there is the authenticity the listener feels with the music. I use the word 'authentic' here to mean in the individualistic sense. Participants feel the music was authentic to them; the music connects with their own thoughts and feelings. Furthermore, they also think that the music has a genuine feeling towards, so it was authentic, as in the antonym of fake, participants see or feel fragments of musicians' lives in the music.

It's the feeling one gets [when listening to the music of the three bands]. I might be exaggerating, but I'm not always so sure that I am when I say there is a spiritual connection. It's as though I am not only connecting with my own humanity, but with humanity in the broader sense. (Allsop)

When "The Sexuality of Bereavement" [The Angel and the Dark River, My Dying Bride 1995 Peaceville Records] played I felt like I was listening to something that I was meant to listen to all my life. It felt, as if I just heard the best song ever and well, even today there are only very few songs that bring up that emotion. (Churchill)

I'm trying to think of the line. [Reciting from memory a line from "The Dark Caress", Like Gods of the Sun, My Dying Bride 1996 Peaceville Records]. I always feel like that line sums up a lot of the things I think about my life because for a long time, I was really very mentally ill, genuinely and I'm really lucky to have recovered from that. But I always find it quite hard to escape the things you have done in your past and I always feel like whenever I hear that line, it's me. (Gimzatte) 
Participants state how deeply they feel a connection towards this music and the musicians of the three bands. It is usually the case for the fan that a sense of intimate connection emerges with the music. Showing the participants feeling they can personally relate to this music better demonstrates the rest of the emotional responses' sincerity. I argue that since many participants feel that they almost would have written the music themselves, the rest of the emotional responses become internalized. They are not responding to external symbols but the emotional response is between the individual and the self.

The next response category is feeling of accommodation. This response is where the participant found the music accommodating to what they are feeling and thinking in their own life. The music accomplishes, for the participant, this by providing a mental space for the listener to either help deal with these thoughts and feelings or explore them without interference. The resonance between the listener's emotional state and the music's either aural or lyrical content results in this space. This is one of the overarching responses and it comes up in participants' answers usually attached to a specific emotion. However, there are rare exceptions to this, where the participant feels a sense of belonging without any further specificity.

When I'm depressed, I feel really comfortable listening to them. (Bunting)

There's a connection to anyone who's been seriously down or depressed; and the majesty of the music is that it cannot so much lift the mood but make that mood habitable, if that makes sense. (Burnett)

I enjoy exploring emotions like anger and sorrow. That's where you really get to know someone. I believe that throughout life you'll laugh with 1,000 people and forget most of them. You will never forget someone you've cried with. (Dunham)

It is important to notice that the response is towards the music rather than anything else in the music world. The music gives these participants a space to retreat to their emotions and explore. Importantly, while the music lines up with certain emotions, it "complements" the emotion rather than creating it out of nowhere. Sometimes this complement result in a cathartic experience helping with the dealing of the negative emotion:

Some creations of these bands seem to express my sorrow, depression, and hopelessness. So, it's something like catharsis. Sometimes [these feelings] just cannot be expunged out of me any other way. (Brady)

Got testicular cancer and was diagnosed with depression, needless to say, doom metal was a good friend to have at the time. (Acland)

Doom music doesn't really make me feel sad. But I do find it hauntingly beautiful. Also, some songs-bands have actually helped me get over some tough situations. (Blackmore)

According to these participants, the music becomes a support system to help them go on in their lives in their relatively negative states, and work through the problems.

As long as the world remains unfair, mean and crappy, doom metal will be there to save you. (Bancroft) 
Doom metal's helpful effect again comes forth here in Bancroft's statement. They use the word 'save', which is notable because it suggests an Aesculapian process mapped onto several moods. In this sense, the music can be thought to have an ataractic effect on the listener. This is a common response in this music world. Participants feel that the music calms them down. I use 'calm' to mean in both a downward and an upward trajectory. When the listener is full of energy, then the music brings the energy down; when the listener is not feeling well emotionally, then the music brings the energy up. It levels the emotional state to a normative state in the listener's mind; the music acts medicinal in this sense.

When I'm angry, the music calms me down. When I feel down, the music makes me happier. When I'm happy, it levels me out. (Acland)

Despite being mournful in character, it brings me a sense of calm and ironic joy. A phrase I often joke with my fiancé about (who is also a fan) is how "delightfully depressing" a certain song is, for example. Again, it is a genre of contrasts. (Allsop)

One important common ground emerges as the feeling of melancholy and/or depression. What is interesting about this is that while these negative feelings are present in the music, it usually has the reversed effect, lifting the listener up from that mood into a more balanced state of mind.

I suffer from depression so listening to Paradise Lost makes me happy! (Carlisle)

For some of the participants, the music even has a sling effect: changing their mood to the opposite. Unsurprisingly, most participants talked about the melancholy or depression in the music. I do not discuss these in detail, however, to give the reader an idea of the amount of this particular theme's occurrence in responses, 54 participants mentioned the melancholy in music 95 times, and depression was mentioned 23 times.

Anathema on the other hand always give me the feeling of depression. (Churchill)

As Churchill suggests, the music can have a depressing effect as well. It is not always in an uplifting direction, as stated earlier by other participants (especially Gimzatte and Douglas), the music can be an accompaniment to such moods and emotions.

I find it a shame that more people don't like My Dying Bride, especially boyfriends - it's the type of music I will not force onto others because I know it really brings 99\% of people down. (Bertie)

Bertie's notion illuminates this reverse reaction's function in the music world. If the music brings the majority of outsiders down, then in order for a member of this music world to be indeed a member, a different kind of emotional response is required. The music for the listener becomes a way of non-destructive habitation of the negative feelings. This habitation might embody itself through an escape as well.

I feel like there's nothing important in everyday life; time stops for a while and only the feelings that the music gives become important. Those feelings can take you to another time, to another space. I can live the past, I can see lives of other people, I can travel through time into the future, and to other worlds. (Auden) 
Mostly their music helps to transform everything that is fucked up in this world into some form of art and then find a safe distance to suffering enchanted in sounds and lyrics. (Brady)

Escape from daily life reality is an important function of this music. As observed from these responses, the music helps to liberate the listener temporarily from the negativity or the mundaneness of everyday life. It provides a space to get 'lost' in something else than one's own life.

In contrast, for some participants, the music becomes a tool for introspection:

I'm also not the type that tends to act as if bad things don't exist. I feel that a lot of people don't want to understand this kind of music because it confronts them with things in their life that they don't want to face and ignore by acting like it doesn't exist, while for me it seems better to accept things as they are and draw strength out the fact that there are people with similar experiences that translate those experiences into music. (Dobson)

This music was part of my "human education". They ask the important questions, the "cursed" questions. (Grimshaw)

The music has a confrontational nature according to the fan. It does not confront daily dealings but ideas that outsiders tend to avoid. Grimshaw's idea that it is part of the 'human education' marks an overall view in terms of the themes usually explored in the music. The introspection supported by the music can result in satisfaction:

[I feel immensely satisfied [when listening to the three bands]; perhaps even so far as so say: complete. (Allsop)

I can say that My Dying Bride has been a major part of forming my life since I was 15 and I think I wouldn't be the same person if I did not find them in the past. (Babbage)

When listening to a band like My Dying Bride or Paradise Lost, the feeling should be sadness, depression; yes, I experience those emotions but at the same time, there's an element that brings relief and satisfaction, sometimes pleasure, and glorious happiness. I can understand how they feel when writing a song, when it's recorded and played live, it's a process, a journey, a cathartic experience unlike any other. Once it is done, you can see that the emotions you experienced, the pain, the grief, the loneliness are all transferred and portrayed on a song; it is timeless. (Bancroft)

The satisfaction experienced by the participants already hint to a sense of hope and even happiness. These responses are where the sling effect I mentioned becomes most prominent. Participants insist on highlighting this contrast as well.

How they can combine utter sadness with little glimmer of hope here and there. Don't get me wrong, in music I like the darkness, hopelessness and misery in general. But without that little bit of hope in the middle of total darkness, the music can sometimes be very uninspiring. And after that little hope, the fall into crushing darkness is so overwhelming and that's the thing I like in doom metal. Doom metal gives me a feeling of long-gone hope paying one last visit just to say farewell. (Fowles) 
Fowles mentions hope as 'long-gone', however it comes back with the music, even to 'just say farewell'. The music is a source of hope in this sense, however momentary at the end. This sense of fleeting hope can be considered as another form of escape. However, the music becomes a significant source of hope for others:

[Paradise Lost's] music is a source of inspiration for me, a way to survive, and a way to overcome negative things in life. (Davies)

Doom metal is the lowest form of suffering in music and rhythms, but can bring out the highest form of hope for lost souls. (Bart)

This 'highest form of hope' becomes joy and even happiness in due course for the fan:

I feel happy. The sadder the music and lyrics, the soothing it normally is for me. (Camden)

I feel really good [when listening to the three bands], as if someone holds me and understands me. (Pablo)

Interestingly, participants seem relatively confused or inarticulate as to why they actually feel happy when listening to this music, however, Pablo gives a possible explanation to this question. A sense of solidarity is common among the fans of this music. As one participant says the music can be part of the 'soul' of the fan.

I feel understood and a little bit less alone in this world when I listen to those bands. (Hartley)

The music again accompanies the fan through the reality of life resulting in a sense of connection. Haldane's statement almost contains divine connotations in relation to the music. While this is a rare response, this idea can become an ideal for the fan:

Anathema is love. And with this love that I listen makes me spread love too for the people around me. (Crabtree)

\section{Conclusion}

These are the fan members' emotional responses to their own community, the music, and the external communities. To recapitulate, the music for the fan is a significant part of their lives. The music can be a potent source of positivity in the fan's life. It has medicinal and even cathartic effects of people's lives. There appears to be also a dissonance between the surface emotions in music and these emotions' reflection on the fan. The 'genre of contrasts' that is death/doom seems to have achieved a contrast in the emotional side of the music as well. I discussed the emotional responses to demonstrate how emotional responses can become conventions in music worlds. Firstly, even though almost half of the participants do not think or want themselves to be part of a smaller community than metal as a whole, or sometimes even at all, similar emotional responses given to same symbolic phenomena, i.e. the music, suggest the existence of a social construct, i.e., a music world. The positional conflict discussed further strengthen this idea. This demonstrates how emotional responses can become bases for feelings of belonging in a community. 


\section{References}

Atkinson, P. and Housley, W. (2003), Interactionism: An Essay in Sociological Amnesia, London: SAGE Publications.

Becker, H. S. (2008), Art worlds (Updated and expanded 25th anniversary ed.), London: University of California Press.

Bell, V. (1999), 'Performativity and Belonging: An Introduction', on V. Bell (ed), Performativity and Belonging, London: SAGE Publications Inc, pp. 1-10.

Blumer, H. (1998), Symbolic Interactionism: Perspective and Method, London: University of California Press.

Bottero, W. and Crossley, N. (2011), 'Worlds, Fields and Networks: Becker, Bourdieu and the Structures of Social Relations', Cultural Sociology, 5:1, pp. 99-119.

Charon, J. M. (2010), Symbolic interactionism: an introduction, an interpretation, an integration (10th edition ed.), London: Prentice Hall.

Crossley, N. (1998), 'Emotion and communicative action: Habermas, linguistic philosophy and existentialism', in G. Bendelow and S. J. Williams (eds), Emotions in Social Life: Critical Themes and Contemporary Issues, New York, NY: Routledge, pp. 16-38.

(2015a), 'Music Worlds and Body Techniques: On the Embodiment of Musicking. Cultural Sociology, 9:4, pp. 471-492.

(2015b), Networks of sound, style and subversion: The punk and post-punk worlds of Manchester, London, Liverpool and Sheffield, 1975-80, Manchester: Manchester University Press.

Crossley, N. and Bottero, W. (2015a), 'Music Worlds and Internal Goods: The Role of Convention', Cultural Sociology, 9:1, pp. 38-55.

(2015b), 'Social Spaces of Music: Introduction', Cultural Sociology, 9:1, pp. 319.

Crossley, N., McAndrew, S. and Widdop, P. (eds) (2014), Social networks and music worlds, London: Routledge.

de Rivera, J. (2014), 'Emotion and the formation of social identities', in C. von Scheve and M. Salmela (eds), Collective Emotions: Perspectives from Psychology, Philosophy and Sociology, New York, NY: Oxford University Press, pp. 217-231.

Denzin, N. K. (1992), Symbolic Interactionism and Cultural Studies: The Politics of Interpretation, Oxford: Blackwell Publishers.

Gilmore, S. (1990), 'Art Worlds: Developing the Interactionist Approach to Social Organization', in H. S. Becker and M. M. McCall (eds), Symbolic interaction and cultural studies, Chicago: The University of Chicago Press, pp. 148-178.

Hagen, R. (2011), 'Musical style, ideology, and mythology in Norwegian black metal', in Wallach, J., Berger, H., and Greene, P. (eds), Metal Rules the Globe. Durham, NC: Duke University Press.

Kahn-Harris, K. (2004), "The "failure" of youth music culture: Reflexivity, music, and politics in the black metal scene', European Journal of Cultural Studies, 7:1, pp. 95-111.

(2007), Extreme Metal: Music and Culture on the Edge. Oxford: Berg.

Kuppens, A. H. and van der Pol, F. (2014), "True" black metal: The construction of authenticity by Dutch black metal fans', Communications, 39:2, pp. 151-167.

Larsson, S. (2013), 'I bang my head therefore I am: Constructing individual and social authenticity in the heavy metal subculture', Young, 21:1, pp. 95-110.

McAndrew, S., Widdop, P. and Stevenson, R. (2015), 'On jazz worlds', in N. Crossley, S. McAndrew and P. Widdop (eds), Social Networks and Music Worlds, Oxon: Routledge, pp. 217-243. 
O'Shea, S. (2015), 'Embracing difference in feminist music worlds: a Ladyfest case study', in N. Crossley, S. McAndrew and P. Widdop (eds), Social Networks and Music Worlds, Oxon: Routledge, pp. 122-144.

Prior, N. (2015), "'It's A Social Thing, Not a Nature Thing": Popular Music Practices in Reykjavik, Iceland', Cultural Sociology, 9:1, pp. 81-98.

Spracklen, K. (2015), Digital leisure, the Internet, and popular culture: Communities and identities in a digital age, London: Palgrave MacMillan.

Terrorizer Magazine 1-255 (1993-2016), London: Dark Arts Ltd.

van der Löwe, I. and Parkinson, B. (2014), 'Relational emotions and social networks', in C. von Scheve and M. Salmela (eds), Collective Emotions: Perspectives from Psychology, Philosophy and Sociology, New York, NY: Oxford University Press, pp. 125-140.

Varas-Diaz, N. and Scott, N. (eds) (2016), Heavy Metal Music and the Communal Experience, New York, NY: Lexington Press.

Venkatesh, V., Podoshen, J., Urbaniak, K., and Wallin, J. (2015), 'Eschewing Community: Black Metal', Journal of Community \& Applied Psychology, 25, pp. 66-81.

Wallach J., Berger, H., and Greene, P. (2011), Metal Rules the Globe. Durham, NC: Duke University Press.

Yavuz, M. S. (2016), 'Gloomy Divergence: Death Doom Metal as Dark Leisure', Paper presented at the Extreme Music Research Seminar Series, University of Southern Denmark, the Performances of Everyday Living Research Group, Accessible from <https://c.deic.dk/p11xfkrjh5e/> [password: music]. Accessed 15 June 2016. 